\title{
Age-Related Differences in Executive Functions Within High-Level Youth Soccer Players
}

\author{
ADAM BEAVAN ${ }^{1,2}$ | JAN SPIELMANN ${ }^{3}$ | JAN MAYER ${ }^{3}$ | SABRINA SKORSKI ${ }^{1}$ | TIM MEYER ${ }^{1}$ | JOB FRANSEN ${ }^{4}$ | \\ 1 Institute of Sports and Preventive Medicine, Saarland University, Saarbrücken, GERMANY. \\ ${ }_{2}^{2}$ Think Tank, DFB-Akademie (Deutscher Fußball-Bund), Frankfurt, GERMANY. \\ ${ }^{3}$ TSG 1899 Hoffenheim, Zuzenhausen, GERMANY. \\ ${ }^{4}$ Sport and Exercise Discipline Group, Faculty of Health, University of Technology, Sydney, AUSTRALIA.
}

Correspondence to: Adam Beavan. Institute of Sports and Preventive Medicine, Saarland University, Campus, Building B 8-2, 66123, Saarbrücken.

email: adam.beavan@uni-saarland.de

https://doi.org/10.20338/bjmb.v13i2.131

\author{
HIGHLIGHTS \\ - Positive relationship between Executive \\ Functions (EF), age and playing experience. \\ - Magnitude of change in EF is larger between \\ the younger cohorts. \\ - Older athletes can better negate unimportant \\ information from incongruent precues. \\ - EF sum score calculating all tests together \\ can differentiate between age-groups.

\section{ABBREVIATIONS} \\ ANOVA Analysis of variance \\ EF Executive Functions \\ Exp Experience playing soccer \\ MANOVA Multivariate Analyses of Variance \\ PCRTT Precued response time task \\ RSTT Reactive stress tolerance task \\ SSRT Stop signal reaction time
}

\begin{abstract}
BACKGROUND: It is less-common for athletes to be assessed on their ability to detect and process implicit sources of information.

AIM: This study aimed to investigate age-group differences in executive functions within youth soccer players, with the inclusion of a new implicit precued choice response time task.

METHOD: Seventy-four male soccer players: U12 ( $n=15)$, U13 $(n=17), U 17(n=21)$ and U19 $(n=21)$ representing a representing a youth academy of an elite German Bundesliga club participated in this study. Players conducted a battery of computer-based cognitive function tests: a precued choice response time task (PCRTT), a stop signal reaction time task (SSRT), a multiple-object-tracking task (Helix), and a reactive stress tolerance task (RSTT).

RESULTS: The MANOVAs revealed a multivariate effect of age group on the RSTT $(p<0.001, E S=0.38)$ and the SSRT $(p<0.001, E S=0.20)$. A one-way ANOVA revealed an age group effect for response accuracy in the Helix $(p=0.01, E S=0.14)$. Lastly, a within-subjects effect of congruency on the PCRTT $(p<0.001, E S=0.41)$ and a between-subjects effect of age group ( $p=0.008$, ES $=0.15$ ) was observed.

CONCLUSION: The results provided support for including an implicit precueing task, while the overall testing demonstrated that the magnitude of the increase in executive functions between ages was greater across the younger age groups compared to the older age groups.
\end{abstract}

\section{INTRODUCTION}

In a sporting context, executive functions (EF) are a sub category within the theoretical frame work of the cognitive component approach, and are often described as 'game intelligence' 1. Vestberg, Gustafson, Maurex, Ingvar, Petrovic ${ }^{2}$ first noted that the existing body of research lacked understanding of the importance of general cognitive abilities within an athletic population. The authors proceeded to test high and low division adult soccer players on a series of non-sport specific cognitive function tests. The results revealed that soccer players outperformed the norm group for both men and women, and high division players outperformed the low division players. Since Vestberg and colleagues' paper on EF in sport, interest in measuring EF has grown.

One EF that talented soccer players consistently outperformed their lower-level counterparts on is response inhibition (i.e. the suppression of an ongoing motor response) 2,3 , among others. Thus, enhanced response inhibition may be a contributor to successful sporting performance in more talented players across all age groups, and therefore

\begin{tabular}{l|l|l|l|lc}
\hline Beavan et al & 2019 & VOL.13 & N.2 & https://doi.org/10.20338/bjmb.v13i2.131
\end{tabular}


advocates for more research to investigate this EF. The importance of response inhibition in sport may be attributed to the role that it plays in the decision-making process ${ }^{4}$. The ability to inhibit a response results in players making fewer errors by being able to suppress acting on a decision; which is typical in soccer when a defender suddenly guards the intended receiver of a pass, and a new decision must immediately be created. Response inhibition in the EF research has commonly been assessed using simple or twochoice motor response tasks ${ }^{5}$. However, a simple motor response may not be representative of the stimulus-response a team-sport athlete encounters in-situ. Accordingly, a multiple-choice motor response task test may better reflect performance, as players must decide rapidly which decisions to act upon and which decisions to suppress while presented with a variety of options ${ }^{6}$. Moreover, not only is the task complexity simplified, the current response inhibition tests such as the stop-signal reaction test are explicit in nature. It may be speculated that the vast majority of stimuli which athletes are exposed to are hidden within the sporting environment (i.e. implicit rather than explicit), as it is impossible to consciously attend to every stimulus. Many stimuli go unnoticed during a game that may non-consciously change and/or challenge the athlete's sporting performance ${ }^{7}$. Therefore, the development of a new EF test that measures the impact that implicitly perceived visual cues on response time has value.

Understanding the influence that non-attentively perceived cues have on motor performance requires the contribution of the paradigm in cognitive science known as 'precueing'. Precueing is the effect that a presented stimulus has on participants' subsequent decision-making or motor behaviour, albeit an explicit or implicit stimulus ${ }^{8}$. A precue can influence a decision at a non-conscious level, leaving the participant with no subjective experience of having their decisions altered or to some extent, delayed ${ }^{7}$. For instance, in an attempt to prepare the player in possession of the ball for the movement that will occur next, a teammate may point towards their intended direction prior to the initiation of a run. However, whether the player in possession of the ball consciously or non-consciously registers the teammate's hand gesture prior to the run is not always certain.

The first studies on the effects of advanced visual information have demonstrated that if this information provides accurate information about the subsequent stimulus (congruent), it improved reaction times in comparison to non-cued trials ${ }^{8}$. Opposingly, response times were impaired if the precue and stimulus contradicted each other (incongruent) ${ }^{9}$. Although precueing has been extensively researched in mainstream psychology; the transition of research into a sporting domain may improve the understanding of response inhibition in athletes ${ }^{10}$.

Despite the advances of knowledge of EF in athletes, there is another noteworthy limitation. Previous methodologies have used a relatively high variation of participants' age distribution within each group. For example, Vestberg, Reinebo, Maurex, Ingvar, Petrovic 11 grouped players age ranging from 12-19 years together, and it has not yet been investigated whether more specific age-group (i.e. stratified by distinctive birth years) differences are revealed in a homogenous population of high-level athletes. From research sourced from a cognitive science domain, EF are still developing rapidly during the adolescent phase ${ }^{12}$. In course of normal aging, early adolescents experience an increased effectiveness to engage in deliberate, goal-orientated thought and action, and these changes are have been reported to be significantly improved between children (mean age $=8$ years old) and young adults (mean age $=22.3)^{13}$, yet more specific age groups are not 
provided. Furthermore, the enhanced ability to differentiate between goal appropriate responses and goal inappropriate responses that must be supressed also continues to improve throughout the adolescent phase ${ }^{14}$, reflected by reduced reaction times on measures of response inhibition. Accordingly, these studies provide support towards not grouping players with differently developed EF coupled with various levels of domainspecific experience. Contrastingly, identifying specific age group reference values may provide more of a justification of which age groups share similar or distinctive EF to be combined in future studies if required.

Therefore, the aims of this study were threefold. First, to investigate age-group differences on EF tests in a homogenous population of talented youth soccer players. It is hypothesised that performance on EF tests will be greater in the older groups, as more domain specific experience is expected to transfer into better EF performance. The second aim was to examine the influence of an implicit precue on response times in a precued response time task (PCRTT) as measuring implicit response processes compared to explicit measures may be more appropriate to sports where fast and accurate responses are required. It is further hypothesised that the increase in domain specific experience will also transfer into older players to act on correct information whilst also negate unimportant information, demonstrated by faster reaction times on the PCRTT. The third aim was to develop an overall EF sum score, allowing practitioners to more easily interpret and convey the results of tests to coaches and players alike.

\section{MATERIAL AND METHODS}

\section{Participants}

Seventy-four youth male soccer players (means $\pm \mathrm{SD}$; Age; years of experience playing soccer $=$ Exp) from four age groups: U12 $(n=15 ;$ Age $=10.3 \pm 0.6 ; \operatorname{Exp}=6.4 \pm$ 1.7), U13 ( $n=17 ;$ Age = 11.2 $\pm 0.5 ; \operatorname{Exp}=7.6 \pm 1.7)$, U17 ( $n=21 ;$ Age = $15.2 \pm 0.3$; Exp: $11.6 \pm 2.5)$ and $U 19(n=21 ;$ Age $=16.7 \pm 0.5 ; \operatorname{Exp}=12.9 \pm 2.2)$ representing a youth academy of an elite German Bundesliga club participated in this study. Prior to commencement of this study, informed consent for all players was received, and the Institutional Ethics Committee approved this study.

\section{Procedures and apparatus}

Players conducted a battery of cognitive function tests. Each group was assessed on a separate day in the same week during pre-season. Each player was assigned to a cognitive assessment and rotated to the next free assessment. One staff member remained at each assessment station to give standardized instructions and monitor each player's performance. Each assessment had a standardized familiarisation protocol prior to commencing the experimental trials.

\section{Vienna Test System: Determination Test}

The determination test (Schufried $\mathrm{GmbH}$, Austria) is a complex multi-stimuli reaction test involving the combination of five different coloured stimuli and two acoustic signals (2000 Hz high and $100 \mathrm{~Hz}$ low tone) for finger pressing, and two pedal stimuli for the feet. These stimuli corresponded to the pressing of appropriate buttons on the response panel and foot pedals. The determination test aims to measure reactive stress 
tolerance and the associated reaction speed. The participant must remain composed whilst the quick succession of the single pairing of stimuli and response lasting four minutes. 'Correct responses' describes the total number of accurate responses within the four minutes, and 'response time' is the median response time (s) from the appearance of a stimulus to pressing of the correct button.

\section{Vienna Test System: Response Inhibition Test}

The response inhibition test (Schufried $\mathrm{GmbH}$, Austria) uses a stop signal paradigm. In each trial, the player is presented with an arrow either pointing left or right, to which he must respond by pressing the corresponding button. Each arrow is displayed for one second, and the time before the subsequent arrow appears is also one second. Seventy-six stimuli are 'go trials', with the other 24 stimuli having a tone at a pitch of $1000 \mathrm{~Hz}$ for $100 \mathrm{~ms}$ (stop signal). The player must then supress the already initiated response, known as 'stop trials'. The time between the presentation of the stimulus and the tone is dependent on the player's performance, being that if the player responds correctly to a stop signal trial, the interval for the next stop stimuli will occur $50 \mathrm{~ms}$ later, and vice versa. Therefore, the correct response to the stimuli will continually progress in difficulty (minimum $50 \mathrm{~ms}$; maximum $350 \mathrm{~ms}$ ). The dependent variable that reflects the latency of the inhibitory process is stop signal reaction time (SSRT). The SSRT is calculated by deducting the mean stop signal delay from the mean reaction time (s).

Helix

The Helix (SAP, Walldorf, Germany) is a multiple object tracking assessment in which participants are asked to track multiple players at once. The player stands facing a $180^{\circ}$ curved screen ( $7 \mathrm{~m}$ width $\times 2.16 \mathrm{~m}$ height) and must track four out of eight players. Simulated players run around a soccer field for eight seconds in a randomized fashion and return to back to the start line up. Players must then choose the four players they had to track. Players had four practice trials, and ten marked trials. The maximum score is 40 .

\section{Precued Choice Response Time Task}

Participants were required to press the button on a joystick panel associated with a stimulus circle presented on the laptop screen as fast and accurate as possible. The PCRTT developed using Unity software (Unity, Version 5.4.0f3, 2016). Four blank stimulus circles were presented in a horizontal line, with one circle turning yellow in colour after a randomised (2-4 second) fore-period length. Each circle each had a diameter of 512 pixels and an edge width of 5 pixels on a 13.2-inch display. Prior to the appearance of the stimulus, a three second countdown timer was shown. After the appearance of the four stimulus circles, a small dot was appeared for $43 \mathrm{~ms}$ in the centre of one stimulus circle, $86 \mathrm{~ms}$ prior to the circle turned yellow. The duration of the precue was based on prior research supporting that precue duration below the $100 \mathrm{~ms}$ threshold are suitable to be used as unconscious precues ${ }^{15}$, and a 43 ms precue has been identified as an appropriate precue length in research involving cognitive responses ${ }^{16}$.

Twenty-four trials were conducted. Twelve trials had the small dot appear in the same circle as the yellow dot (congruent) and the other twelve trials had the dot appear in a different circle as the yellow dot (incongruent). Response time (given in ms) was measured as the duration between the appearance of the stimulus circle (turned yellow) on 
the computer screen and the moment the button was pressed by the participant. A visual depiction of the task used can be found in Figure 1.

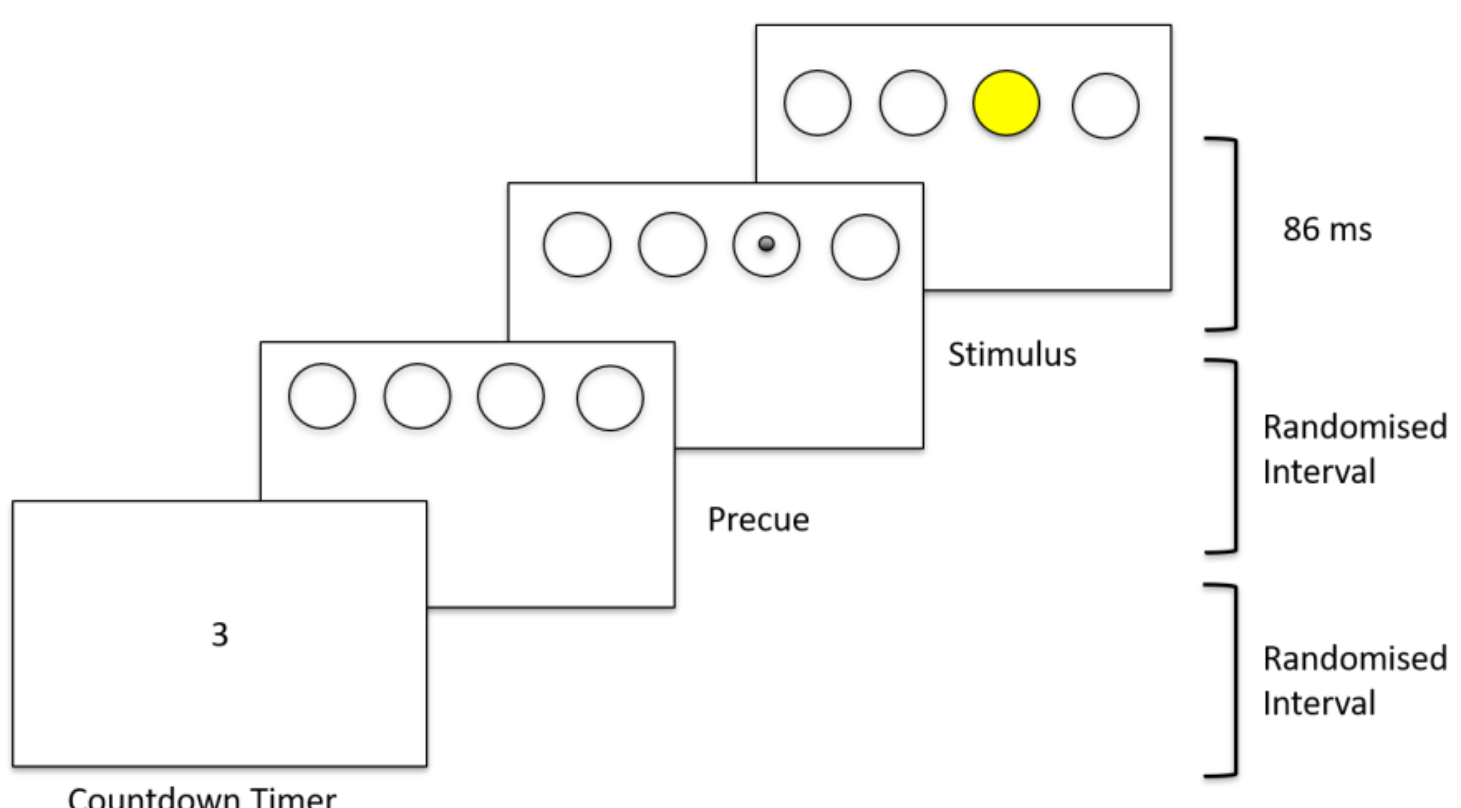

Figure 1. Depiction of the Precued Choice Response Time Task.

\section{Statistical Analysis}

Following data collection, participant responses were initially analysed according to their accuracy. Responses that did not correspond with the stimulus circle (i.e. when a false response was given) were considered incorrect and the response time of the respective trial was discarded due to the low frequency of incorrect responses $(n=53)$. Furthermore, to highlight instances in which the participants missed the controller button or did not press it sufficiently, an outlier labelling rule was used following the methods outlined by Hoaglin, Iglewicz, Tukey ${ }^{17}$, and applied on an individual basis to limit within subject variance. Furthermore, the interquartile range was multiplied by 1.5 , and trials with response times beyond the $25^{\text {th }}$ and $75^{\text {th }}$ percentiles \pm the inter-quartile range were considered outliers and therefore discarded $(n=108)$. The remaining raw responses $(n=$ 1615) from this test were grouped according to 'condition' (i.e. congruent or incongruent trials), and the mean of the correct responses from each participant in each condition was computed.

Normalized values were calculated from z-scores for all items as per: Normalized score $=100+\left(Z\right.$-score $\left.{ }^{\star} 15\right)$. When larger numbers represented poorer scores, the Z-scores were inversed before normalization, so a higher value was associated with a better score. These normalized values were then used in two factor analyses to develop a total executive function sum score (EF sum score) for all players. An exploratory factor analysis used principal component analysis with a varimax rotation to determine the number of factors revealed within all EF assessments to assess the feasibility of one overarching EF factor, a second confirmatory factor analysis then investigated item loadings when all items 
Brazilian Journal of Motor Behavior

were forced to load onto a single factor. Items were discarded when they were deemed to be 'unimportant', i. e. when their communality was found to be lower than 0.40 . From the final factor analysis, a new EF variable was developed using each individual item's factor loading as a weighting system.

Finally, (i) one Repeated Measures Analysis of Variance, (ii) two Multivariate Analyses of Variance (MANOVA) and (iii) two one-way Analysis of Variance (ANOVA) were used to investigate age-group differences in: (i) PCRTT response time where congruent-incongruent scenarios were included as a within-subjects variable, (ii) Determination Test performance with response time and correct responses entered as dependent variables and Vienna Test performance with start-stop response time and response time as dependent variables, and (iii) Helix performance score and the newly developed EF sum score. Bonferroni corrections were used to investigate multiple comparisons between age groups and partial eta squared effect sizes were used throughout to investigate the magnitude of any observed effects using Cohen ${ }^{18}$ guidelines for interpreting effect sizes: $0.01-0.06=$ small effect, $0.06-0.14=$ moderate effect and $>0.14=$ large effect. In all analyses, partial eta squared effect sizes were calculated and the significance level was set at $p<0.05$. All statistical analyses were performed using IBM SPSS Statistics for Windows, Version 24.

\section{RESULTS}

The descriptive statistics and results of (M)ANOVAs for the EF tests can be found in Table 1.

Table 1 - Means \pm standard deviations (95\% confidence intervals), and results of (M)ANOVAs for the executive function tests.

\begin{tabular}{|c|c|c|c|c|c|}
\hline Test & Variable & U12 (n = 15) & U13 (n = 17) & U17 (n = 21) & U19 (n = 21) \\
\hline \multirow{2}{*}{ PCRTT } & Congruent RT (ms) & $\begin{array}{c}0.590 \pm 0.059 \\
(0.562-0.619)\end{array}$ & $\begin{array}{c}0.578 \pm 0.065 \\
(0.554-0.603)\end{array}$ & $\begin{array}{c}0.547 \pm 0.047 \\
(0.523-0.571)\end{array}$ & $\begin{array}{c}0.537 \pm 0.053 \\
(0.512-0.561)\end{array}$ \\
\hline & Incongruent RT (ms) & $\begin{array}{c}0.612 \pm 0.056 \\
(0.582-0.641)\end{array}$ & $\begin{array}{c}0.607 \pm 0.069 \\
(0.582-0.632)\end{array}$ & $\begin{array}{c}0.569 \pm 0.052 \\
(0.544-0.594)\end{array}$ & $\begin{array}{c}0.558 \pm 0.049 \\
(0.533-0.582)\end{array}$ \\
\hline \multirow{2}{*}{$\begin{array}{l}\text { Determination } \\
\text { Test }\end{array}$} & Correct Answers (n) & $\begin{array}{c}215.07 \pm 25.04 \\
(201.20-228.93)\end{array}$ & $\begin{array}{l}238.78 \pm 32.477 \\
(222.63-254.93)\end{array}$ & $\begin{array}{c}263.90 \pm 29.64 \\
(250.41-277.40)\end{array}$ & $\begin{array}{c}291.14 \pm 41.220 \\
(272.38-309.91)\end{array}$ \\
\hline & $\mathrm{RT}(\mathrm{ms})$ & $\begin{array}{c}0.835 \pm 0.066 \\
(0.798-0.871)\end{array}$ & $\begin{array}{c}0.758 \pm 0.096 \\
(0.710-0.805)\end{array}$ & $\begin{array}{l}0.651 \pm 0.055 \\
0.626-0.677)\end{array}$ & $\begin{array}{c}0.619 \pm 0.065 \\
(0.589-0.648)\end{array}$ \\
\hline \multirow{2}{*}{$\begin{array}{l}\text { Response } \\
\text { Inhibition Test }\end{array}$} & SSRT (ms) & $\begin{array}{c}0.239 \pm 0.101 \\
(0.183-0.295)\end{array}$ & $\begin{array}{c}0.204 \pm 0.696 \\
(0.174-0.237)\end{array}$ & $\begin{array}{c}0.134 \pm 0.054 \\
(0.109-0.158)\end{array}$ & $\begin{array}{c}0.117 \pm 0.045 \\
(0.097-0.138)\end{array}$ \\
\hline & $\mathrm{RT}(\mathrm{ms})$ & $\begin{array}{c}0.547 \pm 0.064 \\
(0.511-0.582)\end{array}$ & $\begin{array}{c}0.503 \pm 0.100 \\
(0.456-0.550)\end{array}$ & $\begin{array}{c}0.446 \pm 0.074 \\
(0.412-0.479)\end{array}$ & $\begin{array}{c}0.422 \pm 0.046 \\
(0.402-0.443)\end{array}$ \\
\hline Helix & Helix (\% correct) & $\begin{array}{c}76.00 \pm 7.12 \\
(72.07-79.94)\end{array}$ & $\begin{array}{c}75.24 \pm 7.82 \\
(71.68-78.80)\end{array}$ & $\begin{array}{c}81.79 \pm 8.07 \\
(78.11-85.46)\end{array}$ & $\begin{array}{c}81.79 \pm 8.30 \\
(78.01-85.56)\end{array}$ \\
\hline Total & EF Sum Score (AU) & $\begin{array}{c}406.71 \pm 36.42 \\
(387.41-426.02)\end{array}$ & $\begin{array}{c}437.58 \pm 49.74 \\
(419.45-455.72)\end{array}$ & $\begin{array}{c}485.87 \pm 31.77 \\
(469.55-502.19)\end{array}$ & $\begin{array}{c}506.44 \pm 53.29 \\
(490.12-522.75)\end{array}$ \\
\hline
\end{tabular}

Note: AU= Arbitrary Unit; PCRTT = Precued Choice Response Time Task; EF = Executive Functions; RT = Response Time; and SSRT = Stop Signal Response Time; ES = partial eta squared effect sizes. ${ }^{*}=p<0.05 ;{ }^{* *}=p<0.001$

\begin{tabular}{l|l|l|l|ll}
\hline Beavan et al & 2019 & VOL.13 & N.2 & https://doi.org/10.20338/bjmb.v13i2.131
\end{tabular}


Vienna Test System: Determination Test

Results from a MANOVA revealed a multivariate effect of age group on the Determination Test $\left(F_{(6,140)}=11.670, p<0.001, E S=0.38\right)$. Further univariate analysis revealed a significant age group effect for number of correct responses $\left(F_{(3,71)}=17.453\right.$, $p=<0.001$, $E S=0.42)$ and response time $\left(F_{(3,71)}=33.942, p=<0.001, E S=0.59\right)$. Post-hoc analyses demonstrated that the $\mathrm{U} 12$ age group had a significantly lower number of correct responses than the U17 $(p=<0.001)$ and $U 19(p=<0.001)$ age groups, while the U13 had poorer scores than the U19 group $(p=<0.001)$. Additionally, the U12 group's response time was significantly slower than the U13 $(p=0.018), U 17(p=<0.001)$ and $U 19(p=<0.001)$, and the U13 group's response times were significantly slower than the U17 $(p=<0.001)$ and U19 $(p=<0.001)$ group.

Vienna Test System: Response Inhibition Test

A MANOVA revealed a significant multivariate effect of age group on Vienna Test System Response Inhibition Test $\left(F_{(6,144)}=6.142, p<0.001, \quad E S=0.20\right)$. Subsequent univariate analysis demonstrated a significant effect of age group on $\operatorname{SSRT}\left(F_{(3,73)}\right)=13.172$, $p=<0.001$, ES $=0.35)$ and response time $\left(F_{(3,73)}=10.338, p=<0.001, E S=0.30\right)$. Post-hoc analyses demonstrated that the SSRTs were significantly slower in both the younger groups compared to the older groups. More specifically, the U12 group was slower compared to the U17 $(p=<0.001)$ and the U19 $(p=<0.001)$ groups, while the U13 group was also slower than the U17 $(p=0.005)$ and U19 $(p=<0.001)$ groups. Furthermore, response times were significantly slower in the U12 group than in the U17 $(p=0.001)$ and $\mathrm{U} 19(p=<0.001)$ group, and also the U13 group was slower compared to the U19 $(p=0.005)$ group.

\section{Precued Choice Response Time Task}

The repeated measures ANOVA did not reveal a significant interaction effect of congruency ${ }^{*}$ age group $\left(F_{(3,74)}=0.33, p=0.80\right.$, $\left.E S=0.01\right)$. However, this analysis did reveal a significant within-subjects effect of congruency $\left(F_{(1,74)}=51.32, p<0.001\right.$, $\left.E S=0.41\right)$ and a significant between-subjects effect of group $\left(F_{(3,74)}=4.30, p=0.008, E S=0.15\right)$. Post-hoc analyses demonstrated that overall, responses in congruent trials were faster than in incongruent trials. More specifically, U12 players had significantly poorer overall response times than $U 19$ players in both congruent $(p=0.04)$ and incongruent $(p=0.018)$ trials.

Helix

A one-way ANOVA revealed a significant age group effect for response accuracy in the Helix $\left(F_{(3,74)}=4.05, p=0.01\right.$, $\left.E S=0.14\right)$. A trend towards lower response accuracy was observed in the U13 group compared to the U17 ( $p=0.053)$ and U19 $(p=0.053)$ groups, but this failed to reach statistical significance.

Executive function sum score

Based on the confirmatory factor analysis, the following coefficients were derived and were used to calculate an EF sum score that explains $60 \%$ of the variance in the derived factor:

EF sum score $=\left(0.720^{*}\right.$ Response Time Congruent Inverse $)+\left(0.699^{*}\right.$ Response Time Incongruent Inverse $)+\left(0.756^{\star}\right.$ Determination Test Number of Correct Answers $)+$

\begin{tabular}{l|l|l|l|ll}
\hline Beavan et al & 2019 & VOL.13 & N.2 & https://doi.org/10.20338/bjmb.v13i2.131
\end{tabular}


$\left(0.828^{*}\right.$ Determination Test Response Time Inverse $)+\left(0.853^{*}\right.$ SSRT Inverse $)+$ $\left(0.766^{\star}\right.$ Response Inhibition Time Inverse).

The ANOVA revealed an effect of age group on $\operatorname{ExF}$ score $(F(3,70)=25.82$, $p=<0.001, E S=0.53)$. More specifically, U17 and U19 players had better EF than U12 and U13 players (Table 1 and Figure 2).

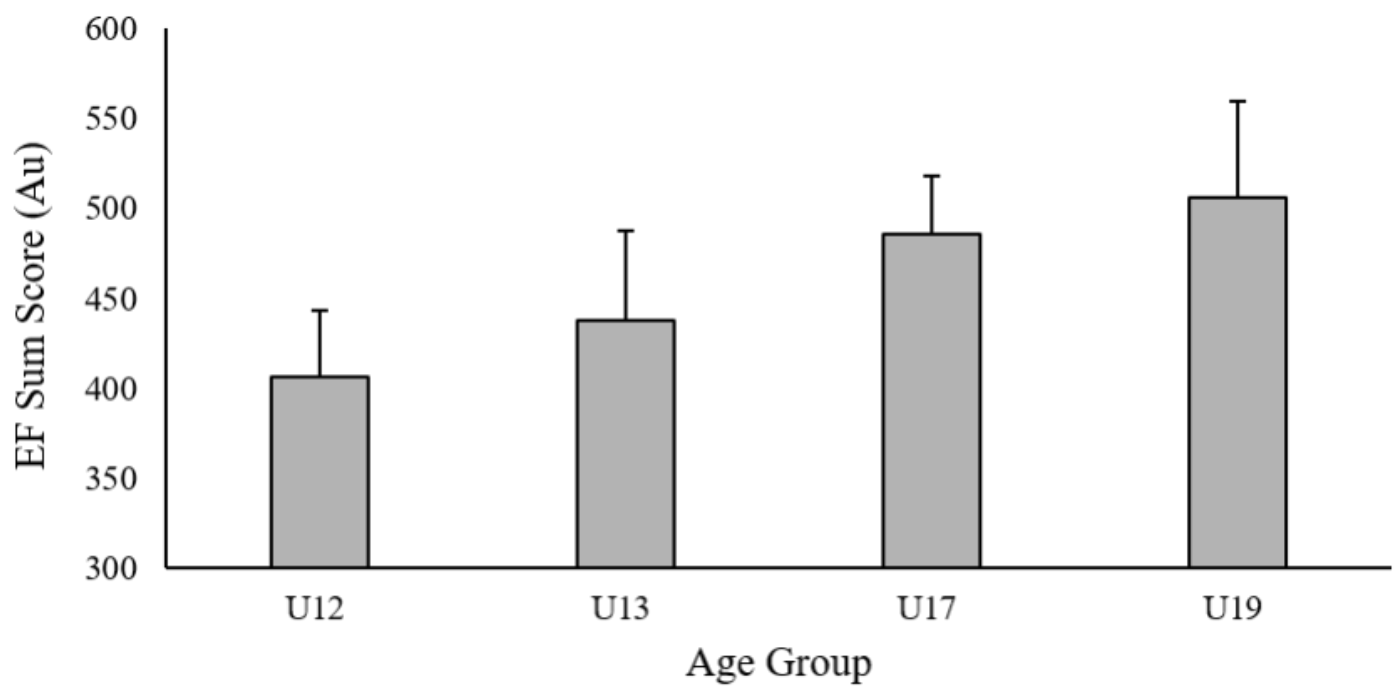

Figure 2. An example of the simplified executive function sum score.

\section{DISCUSSION}

This study used a battery of non-sport specific cognitive function tests within an elite level club's academy to investigate age-group differences on performance. The results from this study supported the hypothesis that older soccer players performed significantly better on EF tests compared to their younger counterparts in a highly talented population. In fact, significant group by performance interaction effects were observed for each test. Additionally, to the authors' knowledge, the present study is the first to demonstrate that implicit stimuli can either enhance or hinder motor behaviour in highly talented youth soccer players based off the congruency of the delivered precue.

In combination, the implicit and explicit response inhibition tests exhibited similar pattern; significant age group effects coupled with large effect sizes indicate a refinement of existing response inhibition ability with increases in age and playing experience. Distinctly, the explicit stop-signal response inhibition test revealed that not only were the younger groups (U12-13) both significantly slower compared to each of the older groups (U17- U19), but also were significantly different between each other. These findings are aligned with previous non-sport specific research stating that the ability to plan and prepare a response are apparent in early adolescence, and that during the adolescent phase is where an improved ability to more consistently filter out irrelevant responses that are not aligned with the desired task goal occurs ${ }^{14}$. Future research should investigate 
whether the magnitude of change between additional age groups that were not included in this study are as prominent during the adolescent phase.

Furthermore, the PCRTT results revealed that during congruent trials, the U12 group was significantly slower than the U19 group; while in the incongruent trials, both younger (U12-13) groups were significantly slower than the U19 group. Collectively these results imply that athletes undergoing development throughout adolescence coupled with gaining more game-specific experience in rapid decision-making scenarios translates to a more refined ability to (i) use congruent precues to their advantage, and (ii) consistently negate unimportant information from incongruent precues than players with less experience. These findings could have important implications for sport coaching. For example, training a player's ability to consistently not act on irrelevant cues throughout the duration of the match has important implications for decision-making in sport. There is a myriad of examples in sport where unimportant information surrounds athletes. For example, players attempting to provide the opponent with false information to gain an advantage (i.e. a pass-fake in a team sport), or visual and auditory distractions from the crowd during a basketball free throw.

The results from the Helix were not clear enough to entirely support previous research that has reported a clear distinction between the level of athletic performance and corresponding fundamental mental capacities for learning an abstract and demanding dynamic scene 19. However, Faubert 19 noted that rapid learning in complex and unpredictable dynamic contexts is one of the critical components required for elite performance. Therefore, the results from the current study imply that the necessary threshold for multiple object tracking performance can already be established from the amount of experience a U12 player has in high-level football (i.e. around 6 years in this case). Supporting research reported that superior perceptual-cognitive skills in elite soccer players compared to sub-elite player were already apparent at the age of nine ${ }^{20}$. Although, it remains difficult to determine if the elite youth players demonstrate these superior cognitive abilities because of a natural born advantage (i.e. nature) or the amount of highquality years of playing experience received prior to the assessments (i.e. nurture) ${ }^{21}$.

The last aim of the study was to overcome the challenge that academics and practitioners face with creating a strategy to more easily convey the results of these cognitive tests for both coaches and players. Overcoming the translation/adoption failure (i.e. where the information is not understood by the intended audience ${ }^{22}$ ) can be difficult as measuring EF requires multiple tests with various interpretations of the results. Although the equation provided within the current study is unique to the battery of tests that were used, it demonstrated that a sum score can be used to differentiate between age groups (see Figure 2). Therefore, academics and practitioners could create their own unique sum score to allow for a smoother translation between the relevant results sourced from the data to the intended audience ${ }^{23}$. From a practical perspective, an allencompassing sum score could provide practitioners with age-group reference values from which players' performance scores could either be compared against other teammates or their own previous test results. This value can also be provided to coaches or players as an easy-to-interpret summary of each individual player or group EF performance, with the ability to provide further information of each test performance if required.

Although this study presents important findings for researchers and practitioners alike, several limitations should be acknowledged. First, this study stratified players only by their respective age groups. Thus, a more in-depth analysis of the potential independent

\begin{tabular}{l|l|l|l|ll}
\hline Beavan et al & 2019 & VOL.13 & N.2 & https://doi.org/10.20338/bjmb.v13i2.131
\end{tabular}


effects such as field position, more detailed playing experience forms and the inclusion of more age groups are needed to form a focus of future research on the role of EF in soccer. Second, despite the validity and reliability of the Vienna Test System being previously confirmed by a variety of studies ${ }^{24-26}$, Baláková, Boschek, Skalíková ${ }^{27}$ called for further investigation of the reliability and validity, stating that the vague design of the test in addition to laboratory conditions is not suitable to predict talent in young soccer players.

\section{CONCLUSSION}

The current study added to this growing body of research by testing the EF of distinct multiple age-groups within a high-level academy. Overall, older athletes with more experience playing soccer had better EF than younger athletes. Furthermore, noticeable improvements in EF performance can also be observed with an increase of one year in age and playing experience during early adolescence. Thus, future studies should take caution when grouping players together with multiple birth years, especially in younger populations where the magnitude of change between ages are more prominent. Lastly, the PCRTT could be used as an additional measure within an EF battery. Choice reaction time tasks are common in to assess reaction times, but only using explicit information. Therefore, the results from this implicit test could further our understanding of how athletes are able to act upon both implicit and explicit sources of visual information and in the future should be compared with additional populations.

\section{REFERENCES}

1. Stratton G. Youth soccer: From science to performance. Psychology Press; 2004.

2. Vestberg $T$, Gustafson $R$, Maurex L, Ingvar M, Petrovic $P$. Executive functions predict the success of top-soccer players. PloS one. 2012;7(4):e34731.

3. Verburgh L, Scherder EJ, van Lange PA, Oosterlaan J. Executive functioning in highly talented soccer players. PloS one. 2014;9(3):e91254.

4. Weinberg RS, Gould D. Foundations of Sport and Exercise Psychology, 6E. Human Kinetics; 2014.

5. Chan RC, Shum D, Toulopoulou T, Chen EY. Assessment of executive functions: Review of instruments and identification of critical issues. Archives of clinical neuropsychology. 2008;23(2):201-216.

6. Travassos B, Araujo D, Davids K, O'hara K, Leitão J, Cortinhas A. Expertise effects on decision-making in sport are constrained by requisite response behaviours-A metaanalysis. Psychol Sport Exerc. 2013;14(2):211-219..

7. Kibele A. Non-consciously controlled decision making for fast motor reactions in sports-A priming approach for motor responses to non-consciously perceived movement features. Psychol Sport Exerc. 2006;7(6):591-610.

8. Posner MI, Snyder CR, Davidson BJ. Attention and the detection of signals. Journal of experimental psychology: General. 1980;109(2):160. 
9. Neumann O, Klotz W. Motor responses to nonreportable, masked stimuli: Where is the limit of direct parameter specification. Attention and performance XV: Conscious and nonconscious information processing. 1994:123-150.

10. Farrow D, Abernethy B. Can anticipatory skills be learned through implicit video based perceptual training? J Sports Sci. 2002;20(6):471-485.

11. Vestberg $T$, Reinebo $G$, Maurex $L$, Ingvar $M$, Petrovic $P$. Core executive functions are associated with success in young elite soccer players. PloS one. 2017;12(2):e0170845.

12. Li S-C, Lindenberger U, Hommel B, Aschersleben G, Prinz W, Baltes PB. Transformations in the couplings among intellectual abilities and constituent cognitive processes across the life span. Psychol Sci. 2004;15(3):155-163.

13. Zelazo PD, Craik FI, Booth L. Executive function across the life span. Acta Psychol. 2004;115(2-3):167-183.

14. Luna B. Developmental changes in cognitive control through adolescence. Advances in child development and behavior. 2009;37:233-278.

15. Vorberg D, Mattler U, Heinecke A, Schmidt T, Schwarzbach J. Different time courses for visual perception and action priming. Proceedings of the National Academy of Sciences. 2003;100(10):6275-6280.

16. Dehaene S, Naccache L, Le Clec'H G, et al. Imaging unconscious semantic priming. Nature. 1998;395(6702):597.

17. Hoaglin DC, Iglewicz B, Tukey JW. Performance of some resistant rules for outlier labeling. Journal of the American Statistical Association. 1986;81(396):991-999. 10.1080/01621459.1986.10478363.

18. Cohen J. Statistical power analysis for the behavioral sciences. 2nd. In: Hillsdale, NJ: erlbaum; 1988.

19. Faubert J. Professional athletes have extraordinary skills for rapidly learning complex and neutral dynamic visual scenes. Scientific reports. 2013;3:1154.

20. Ward P, Williams AM. Perceptual and cognitive skill development in soccer: The multidimensional nature of expert performance. J Sport Exer Psychol. 2003;25(1):93-111.

21. Scharfen HE, Memmert D. Measurement of Cognitive Functions in Experts and EliteAthletes: A Meta-Analytic Review. Applied Cognitive Psychology. 2019.

22. Eisenmann J. Translational gap between laboratory and playing field: new era to solve old problems in sports science. Translational Journal of the American College of Sports Medicine. 2017;2(8):37-43. 10.1249/TJX.0000000000000032.

23. Buchheit $M$. Houston, we still have a problem. International journal of sports physiology and performance. 2017;12(8):1111-1114.

24. Schuhfried G. Sport psychology. Sport test battery for diagnostics and training. In: Mödling: Dr. Schuhfried; 2001.

25. Whiteside A, Parker G, Snodgrass R. A review of selected tests from the Vienna Test System. Selection and Development Review. 2003;19(4):7-11. 
Brazilian Journal of Motor Behavior

26. Ljac V, Witkowski Z, Gutni B, Samovarov A, Nash D. Toward effective forecast of professionally important sensorimotor cognitive abilities of young soccer players. Perceptual and motor skills. 2012;114(2):485-506.

27. Baláková V, Boschek P, Skalíková L. Selected cognitive abilities in elite youth soccer players. Journal of human kinetics. 2015;49(1):267-276. 10.1515/hukin-2015-0129

Citation: Beavan A, Spielmann J, Mayer J, Skorskl S, Meyer T, Fransen J.Age-Related Differences in Executive Functions Within High-Level Youth Soccer Players. BJMB. 2019: 13(2): 64-75.

Editor: Dr Fabio Augusto Barbieri - São Paulo State University (UNESP), Bauru, SP, Brazil; Dr José Angelo Barela São Paulo State University (UNESP), Rio Claro, SP, Brazil; Dr Natalia Madalena Rinaldi - Federal University of Espírito Santo (UFES), Vitória, ES, Brazil.

Copyright: @ 2019 Beavan, Spielmann, Mayer, Skorskl, Meyer, Fransen and BJMB. This is an open-access article distributed under the terms of the Creative Commons Attribution-NonCommercial-NoDerivatives 4.0 International License which permits unrestricted use, distribution, and reproduction in any medium, provided the original author and source are credited.

Funding: There was no funding for this study.

Competing interests: The authors have declared that no competing interests exist.

DOI: 10.20338/bjmb.v13i2.131 